\title{
English Language Learning Strategies of Malaysian Secondary School Students: Implication for Inter-Cultural Communication
}

\author{
Noor Zainab Binti Abdul Razak¹, Mallam Adamu Babikkoi1,2 \\ ${ }^{1}$ Universiti Teknologi, Johor Bahru, Malaysia \\ ${ }^{2}$ Federal College of Education, Yola, Nigeria \\ Email: noorzainab@utm.my, abalbashar5@gmail.com
}

Received 28 January 2014; revised 2 March 2014; accepted 21 March 2014

Copyright (C) 2014 by authors and Scientific Research Publishing Inc.

This work is licensed under the Creative Commons Attribution International License (CC BY). http://creativecommons.org/licenses/by/4.0/

\begin{abstract}
English is unquestionably the contemporary language of science, technology, commerce, intercultural communication and scholarship. It is consists of accomplished growing importance in the world. Consequently, in Malaysia concerned parents, researchers, scientists and instructors that know the inevitable impact English language possess over the academic and socio-economic progress of the students clamour for English proficiency. In Malaysia, English is not only the second language in importance but also a school and college subject, and language of instruction of science and mathematics. Interestingly, ESL/EFL studies nowadays are devoted to finding out techniques employed by learners. It is against this backdrop that this study was carried out to discover strategy use among ESL students in Malaysian secondary schools to look further at the implication of their strategy use with regards to inter-cultural communication. Oxford's SILL Questionnaire was administered to 180 secondary school students and SPSS 7.0 version was used for analysis. Findings reveal the dominance of indirect learning techniques, meaning high anxiety, dependence heavily on peers and teachers to learn English and fewer practice of the oral language. The study recommends the teaching of learning techniques to students and positive exploitation of core-curricular activities that will create and sustain constant practicing of English language among students to facilitate inter-cultural communication.
\end{abstract}

\section{Keywords}

Language Learning Strategies; Inter-Cultural Communication; Malaysian Secondary School Students 


\section{Introduction}

As conscious efforts, thoughts, actions and inactions language learning strategies are used in order to facilitate and enhance learning of the target language. According to Paige et al. (2006) and Cohen (1998), this also includes behaviors and semi-conscious attitude that are intended towards achieving the goal of improving knowledge and understanding of not only the target language but also the culture. Similarly, Fewell (2010) observes that, studies and interest on second/foreign language learning strategies have continuously been growing essentially since it became obvious that employing affective Language Learning Strategy (LSS) has the potentials of positively impacting on ESL/EFL learning. This implies that, in ESL/EFL pedagogy, it is attributable that poor attitudes and ineffective strategy use could lead to poor proficiency and poor academic performance even among the naturally vibrant students. This suggests further that, students' habitual approaches to practicing their capabilities for learning are thought to become necessary in ensuring language competence and performance. And it is apparent that learners' learning strategies are revealed through their study habits. Interestingly, language learning strategies are related to language proficiency and that the more the use of different strategies the more the tendency for a second language learner to improve and be more proficient in both his/her oral communication and composition (Green \& Oxford, 1995; Zhang, 2001).

Language Learning Strategies and Language Pedagogy have been seen to have a direct correlation essentially because understanding the differences in use of strategies between successful learners has its positive pedagogical implications since findings could be used to influence and facilitate the achievement of the less effective learners. Learning strategies are teachable experiences or activities implying that, the identified strategies used by the effective learners can be used to influence and facilitate the teaching of the less-effective learners. Due largely to the growing globalization of the English language along with the established correlation between English language abilities and proficiencies to educational and socio-economic gains, there's an increasing concern for English language proficiency among Malaysians. Because of that there's a dire need to embark on aggressive studies into the student activities with regards to their English language learning right from the lower degree of education, the secondary schools. This will ascertain their levels of activities and establish the appropriateness of the activities in ensuring proficiency and communicative competence among the different races of Malaysia and even as it relates to communication in wider inter-cultural contexts and situations.

No doubt, LLS do influence the development of speaking skills in the target language, through social interaction, planning where to meet and use the target language as well as compensating for the missing language through gestures. Communication is therefore an integral part of LLS. In fact, appropriate use of language learning strategies (LSS) often results in improved proficiency (Thompson \& Rubin, 1996; Oxford et al., 1993). Interestingly, Oxford et al. (1990), pointed that the ESL/EFL leaner can benefit from strategy training, as it will foster greater responsibility and self direction of the learning process, which eventually leads to communicative competence. On the basis of the aforementioned potentials of LLS, Jamieson and Chappelle (1987) are of the opinion that, continuously investigating learners' working styles while they are studying offers an ideal setting for investigating important questions about learners' strategies.

In order to achieve the following dual objectives: Find out ESL strategy use among the students in Malaysian secondary schools and examine the implication of the strategy use in relation to inter-cultural communication, a total of 180 participants were selected to reply to the Questionnaire, which was modified from Oxford's SILL (1990). Data was analyzed while using SPSS version 7. Interestingly, results indicate high mean distribution in respect to employing learning strategies among the school students while learning English language. The most popular learning strategy was the affective and also the least popular was the compensation strategy.

Zhang (2001) maintains that language learning strategies and its related research outcomes have continued to support the theory that learning strategies help ESL learners to be autonomous which consequently enhances their becoming more proficient learners. Zhang investigated the language learning strategies used by the PRC pre-matriculation students in the SM3 intensive English programme run by Centre for English Language Communication, University of Singapore (CELC). Interestingly, his study confirms further that language learning strategies are related to language proficiency and that more the use of different strategies the more the tendency for more language improvement and proficiency in both oral communication and composition. Zhang's findings corroborated earlier findings (Oxford, 1990; McIntyre, 1994; Green \& Oxford, 1995).

It is common that people learn second or foreign language for different reasons or purposes and they learn 
quite differently depending on the interest, demand, goals and motivational drives. Based on the variant demands for the English competence for either academic, social or economic reasons different approaches, different language learning styles and strategies are used to help achieve the required competence in the target language. Language learning strategies are facilitators to easier, faster and as valid approaches to learning a second language regardless of what learner's first language.

Neuliep and McCroskey (1997) posit that intercultural communication is considered as crucial in foreign language learning and communication studies due to what it really signifies, because it seeks to describe the anxiety associated with real or anticipated interaction with people that are from different social and cultural background with you. Lin and Rancer (2003) also realize that intercultural communication is connected with assessing the "intercultural readiness-to-communicate". Intercultural communication can also be carefully associated with Language competence which is seen essentially as a fundamental element. Intercultural communication is greatly restricted due to lack of linguistic competence in the target language (Redmond \& Bunyi, 1991; Sercu, 2002, Olson \& Kroeger, 2001). This implies that, we overcome anxiety when we are confident of our proficiency. The more proficient we are the less inhibition we face in our attempt to communicate inter-culturally or even crossculturally.

\section{Classifications of Learning Strategies That Facilitate Communication Competence}

Communication strategies concentrate on such strategies that facilitate or significantly influence easy processing and application of language competence and performance. According to (Chamot, 1987; Oxford, 1990), language learning and use strategies involves the cognitive, metacognitive, affective, social, memory or compensation. Cognitive strategies usually involving identification, retention, storage, or retrieval of words, phrases, along with other aspects of the second language. Metacognitive strategies cope with pre-assessment and pre-planning, on-line planning and evaluation of ESL/EFL language learning activities, and language use occasions. There is no doubt that, meta-cognition in language learning and language use strategies allow students to manage their very own cognition by planning, organizing, and evaluating the learning process as well as putting the target language into practice. Affective strategies actually regulate feelings, motivation, and attitudes (this involves strategies that help in managing and decreasing the anxiety level experienced especially during communication). Social strategies range from the actions which the learner of a second or foreign language takes to be able to communicate with fellow learners or students with native speakers (this may involve asking natives or more proficient learners questions for clarification and cooperation). Memory strategies involve four mental processes, further subcategorized into 9, namely: creating mental linkages, applying images and sounds, retrieving as well as employing action. For example, a learner remembers the words danger or dangerous when he associates the word to the mental image of fire-burning, accident or attack by robbers. The use of this strategy, using visual images makes it easy for the learner to make a connection between words and phrases with sounds, motions or touches. The compensation strategies essentially are employed when grammatical skill is incomplete. For instance a different form or a verb "boarding" "departure" such as "entering the plane" taking off may be used to convey message. Similarly, learner can make a guess of the meaning of a word/phrases/sentences based on his/her personal experience.

\section{Methodology of Data Collection}

Questionnaire based on Oxford's Strategy Inventory for Language Learning (SILL) was used to collect data for this study. SILL is a widely used instrument in collecting data relating to L2 strategy use and perhaps the most reliable and comprehensive work on language learning strategies (Ellis, 1994) hence it is employed by researchers.

\subsection{Sampled Population of the Study}

The sampled population in this study involved a total of 180 respondents from Public secondary schools in Johor and the selected responded to the questionnaire, which was adapted from Oxford's SILL (1990).

\subsection{Results of the Study}

Data was analyzed using the SPSS version 7.0. Oxford (1990) proposed three aspects of frequency of usage and 
these are categorized into high frequency (3.5 - 5.0), medium frequency (2.5 - 3.49) and low frequency (1.0 2.49). The results of average frequency of all the strategies are compared to conclude on the best strategy used by the respondents. Apparently the respondents in this study employed LLS at different frequencies to facilitate learning of English language. The summary of their pattern of employing LLSs is seen in Table 1.

\section{Interpretation and Implication to Inter-Cultural Communication}

Interestingly the scores above indicate a positive attitude reported in relation to the employment of learning strategies among the respondents while learning English language. In specific terms, the most preferred learning strategy was the affective domain and the least popular was the compensation strategy.

The findings of this study on the level of awareness have not indicated a deviation from a study carried out almost a decade ago. In an earlier study on the effect of learning strategy using among Malaysian secondary school students, Ganakumaran (2003) established that using learning strategies has facilitated understanding in reading comprehension, which is a skill in the English language syllabus of Malaysia. Embi (2000), also emphasize that, proficiency in the TL can better be achieved when the learner goes out to find and use opportunity to practice the language in the reality world (social strategy). This of course involves range of strategies to actualize.

This study indicates that there is a growing awareness among secondary school students in Malaysia in relation to employing learning strategies hence our current result reveals high use of learning strategies at a minimum of 3.5398 mean score. However, it cannot be said that it points at positive communication among respondents.

The implications of the result of this study on inter-cultural communication is that, if affective strategy is highly practiced it means communication (involving compensation strategy) may not be popular. This is because affective strategy does not in itself involve communication or practicing the target language as a learning process but helps in suppressing the anxiety of the Second language learner when he/she comes into performance in the target language. These may include; relaxing through taking deep breath or meditating, to having a language learning diary and sharing of learning feelings with someone.

What is not yet clear and cannot not be revealed through the data was whether the emotional attachment which results into interaction through asking peers, colleagues, teachers or parents means that the communication is been carried out freely among the diverse indigenes of Malaysia, and whether the language that is been used in the interaction was really the target language? We assume they relate with other students from other races in Malaysia since they belong to the same public schools in which all races can attend. Such practice if common is capable of uniting the students and suppressing their level of anxiety, thus give opportunity for communication among diverse cultures to take place. With careful planning this can be achieved.

Oxford (2001) maintains that, meta-cognition in ESL/EFL learning and language use strategies is positive because it provides the opportunity for the learner to take charge of his learning by way of finding out on his own varieties of avenues to use the target language. This implies that, a learner goes to places to get the opportunity to practice the new language. Similarly, when the learner discovers that during conversation a mistake was made he/she uses that as a motivation and do not allow that shortcoming to wear him down. We learn to be proficient through listening and emulating other peoples' speeches and may require that we look for such people to talk to. Often times, to learn a new language we must read more about the language and create clear goals for improvement. If all these and many more as they relate to the domain of meta-cognitive strategy are practiced as reported by our respondents then we could assert that, inter-cultural communication to some extent do take place among the learners.

Table 1. LLS preference of Johor secondary students.

\begin{tabular}{|c|c|c|c|c|}
\hline Domain & $\mathrm{N}$ & Mean & Standard Deviation & Ranking \\
\hline Affective & 180 & 3.7067 & 0.2220 & $1^{\text {st }}$ \\
\hline M-Cognitive & 180 & 3.6591 & 0.1286 & $2^{\text {nd }}$ \\
\hline Social & 180 & 3.6463 & 0.1950 & $3^{\text {rd }}$ \\
\hline Cognitive & 180 & 3.6090 & 0.0840 & $4^{\text {th }}$ \\
\hline Memory & 180 & 3.5403 & 0.1609 & $5^{\text {th }}$ \\
\hline Compensation & 180 & 3.5398 & 0.1878 & $6^{\text {th }}$ \\
\hline
\end{tabular}


As we can see the meta-cognitive strategy of our respondents was ranked second in frequency and as second most popular strategy. This no doubt allows students to manage their very own cognition by planning, organizing, and evaluating their learning process as well as putting the target language into practice. Perhaps due to the Plurality and social make-up of Malaysia as multi-ethnic, multi-lingual, multi-religious and multi-cultural society, it is assumed that academic competition and clamor for excellence is thriving. It is also assumed that parents would often times motivate and supervise the learning activities of their children hence they grow up quite aware of their educational challenges hence the use of meta-cognitive strategies in learning English language.

The social learning strategy which propels interaction among learners was third in ranking/preference indicating an interesting level of interaction among the students especially while learning English language. According to (Oxford, 2001) employing social strategy in ESL/EFL learning implies that the learner is keen in his search for proficiency. Through asking more proficient learners or experts in the target language the learner engages in conversation and interaction. Similarly, when a learner asks experts to correct him/her it implies that he is using the target language otherwise he can't seek for correction. In attempts to using the target language social strategy provides the opportunity for practice and asking questions about or in the target language as well as learning about the culture of the natives. Interestingly, our respondents in this study use this strategy highly. This implies that they use English language in communication. However, the question that still seeks clarification is with whom do the learners practice the target language? Perhaps only a qualitative study will shade more light on this.

As an aspect of communication style, Intercultural communication occurs essentially when people from different cultural background have to communicate or negotiate a business deal. This type of interaction is so crucial because both parties have to understand their differences and act as supposed to. Different races of the world communicate differently. Take an example of Asians. They are characterized by so much respect for elders such that they display that often times through nodding their heads while they listen to someone speak. Sometimes such nodding's meant to serve as compensation or gap filling in communication. To an African or English culture (who is quite expressive) this may be seen as timidity, as it has the tendency to inhibit communication especially where oral expression is really required.

Our findings indicate that, the three strategies that directly involve learning the target language (Cognitive, Memory and Compensation) through some practices that ensure storing, processing and language retrieval were secondary among our respondents. In specific terms, cognitive strategy was fourth most popular strategy and memory fifth with compensation as the least in use. This pattern manifests that our learners are quite weak, full of anxiety in learning the target language although highly aware of the need for proficiency in English language and even try all possible activities to practice communicatively as shown in their self reports. Interestingly though all the strategies are reported to be used on high levels ranging between 3.5398 and 3.6090 mean distributions. According to Noor (2000) it is essential that Teachers understand the type of learner he teaches and how the learner thinks about the learning task. This enables the teachers to maneuver the teaching in accordance with the learners' behaviors, expectations and preferred ways of learning.

\section{Conclusion and Recommendations}

This paper has so far revealed that all the six learning strategies are employed by secondary school students in Johor while learning English language as a second language. The use is at high level which signifies that awareness in terms of employing learning strategies is high. However, when we look at the pattern of the strategy use, we could see that the affective strategy is ranked the most popular strategy in use. This implies that there is anxiety among respondents which is quite not encouraging in relation to intercultural communication. As people need to overcome their anxiety to be able to freely interact in the target language. Similarly, the results point to the fact that respondents do socialize among themselves hence the ranking of the social strategy as second most popular. It means that, the learners do look for those to communicate with which if well coordinated is capable of ensuring effective communications amongst students in Malaysia who are of different and diverse races. Employing social strategy in ESL/EFL learning is an indication of enthusiasm and keenness of the learner in terms of attempting to be proficient. Through asking more proficient learners or experts in the target language the learner engages in conversation and interaction. Meta cognition was third most popular strategy implying that, the learners do take charge of their learning. The three direct strategies that influence understanding, storing and retrieval of linguistic information were found to be used by the respondents in this study but 
with such a pattern that reveal less commitment to cognitive, memory and compensation activities. In specific terms, cognitive strategy was fourth most popular strategy and memory fifth with compensation as the least in use.

Intercultural communication happens when people affected by different cultural towns negotiate shared meanings in interaction. To facilitate intercultural communication among our student teachers should provide useful guidance and opportunities towards ensuring free communication among the diverse races of Malaysia.

Teachers should create awareness among students on the benefits of communication competence. Harmony should be established between the students through galvanizing the student to perform well, have confidence thereby fight anxiety to the barest minimum. This signals that, in order to increase the potentials of the learner and boost his confidence to communicate he/she should be provided with strategy training that will prepare him in that direction. Americans, Britons, Nigerians are quite expressive and essentially easy to come along with compared to Asians.

The non-expressiveness practice among Asians usually results in anxiety which we have seen in the results of this study, where affective strategy was ranked the highest and most popular strategy among the respondents. Anxiety usually occurs when an L2 learner fears to express himself/herself because of fear of making mistakes. Consequently, this kind of person is inhibited from communicating not because he cannot but because he/she has to speak with someone from a different cultural background.

Short plays or performances that will ginger the use of speaking English through core-curricular activities should be promoted.

Records show that, Latin American often times use their hands as they communicate and may even touch you when communicating different from the Asians head-nodding. Interestingly, Africans speak on top of their voices, while Asians are quite more gentle and quite with their expressions. When people from different cultural background must interact and communicate a point of equilibrium must be observed.

As ESL/EFL instructor, you should have to create as numerous authentic situations as you possibly can, especially those situations that will encourage intercultural communication among your students. Therefore, ESL/ EFL instructors need to understand how difficult it might be for the students especially at the secondary school level to really brace up and initiate a discussion with a foreigner and in a foreign language such as English.

For this to be popular among the students who are from different social background must first be encouraged to learn to interact freely among them especially using English language as the bridge. Achieving this could come through a number of activities that stimulates interest and permit students to become effectively integrated to one another by way of various kinds of learning methods.

An alternative choice that ESL/EFL instructors have would help students realize the necessity of possessing communicative competence. For instance, students might be urged to have their own language diary. The procedure need not be as rigorous like a researcher's, however, it will give students a chance to mirror by themselves experience as well as their responses towards the language and culture.

Similarly, teachers of ESL/EFL should be assisted to give in their best by providing them with tour opportunities once in a while where their students could interact with people from different cultural background Malaysians or foreigners, but who are English language's proficient. Malaysia is now a tourist attraction with careful planning this opportunity can be utilized.

\section{References}

Chamot, A. (1987). The Learning Strategies of ESL Students. In A. Wenden, \& J. Rubin (Eds.), Learner Strategy in Language Learning (pp. 71-83). Englewood Cliffs, NJ: Prentice Hall, Inc.

Cohen, A. D. (1998). Strategies in Learning and Using a Second Language. Harlow: Addison Wesley.

Ellis, R. (1994). The Study of Second Language Acquisition. Oxford: Oxford University Press.

Embi, M. A. (2000) Language Learning Strategies: A Malaysian Context. Ph.D. Thesis, Bangi: Universiti Kebangsaan Malaysia.

Fewell, N. (2010). Language Learning Strategies and English Language Proficiency: An Investigation of Japanese EFL University Students. TESOL Journal, 2, 159-174.

Ganakumaran, S. (2003). Literature Programmes in Malaysian Schools: A Historical Overview. In Ganakumaran, S. (Ed.), Teaching of Literature in ESL/EFL Contexts (pp. 27-48). Petaling Jaya: Sasbadi Sdn. Bhd.

Green, J. M., \& Oxford, R. L. (1995). A Closer Look at Learning Strategies, L2 Proficiency, and Gender. TESOL Quarterly, 29, 261-297. http://dx.doi.org/10.2307/3587625 
Jamieson, J., \& Chapelle, C. (1987). Working Styles on Computers as Evidence of Second Language Learning Strategies. Language Learning, 37, 523-544. http://dx.doi.org/10.1111/j.1467-1770.1987.tb00583.x

Lin, Y., \& Rancer, A. S. (2003). Ethnocentrism, Intercultural Communication Apprehension, Intercultural Willingness-toCommunicate, and Intentions to Participate in an Intercultural Dialogue Program: Testing a Proposed Model. Communication Research Reports, 20, 62-72. http://dx.doi.org/10.1080/08824090309388800

McIntyre, P. D. (1994). Toward a Social Psychological Model of Strategy Use. Foreign Language Annuals, 27, $185-195$. http://dx.doi.org/10.1111/j.1944-9720.1994.tb01201.x

Neuliep, J. W., \& McCroskey, J. C. (1997). The Development of Intercultural and Interethnic Communication Apprehension Scales. Communication Research Reports, 14, 145-156. http://dx.doi.org/10.1080/08824099709388656

Noor, Z. A. R. (2000). Motivational Factors and Learners' Strategies in the English as a Second Language Classroom at Universiti Teknologi Malaysia with Special Reference to Computer Assisted Language Learning. Unpublished Thesis, Doctor of Philosophy.

Olson, C. L., \& Kroeger, K. R. (2001). Global Competency and Intercultural Sensitivity. Journal of Studies in International Education, 5, 116-137. http://dx.doi.org/10.1177/102831530152003

Oxford, R. (1990). Language Learning Strategies: What Every Teacher Should Know. New York: Newbury House Publishers.

Oxford, R. (2001). Language Learning Strategies and Styles. In M. Celce-Murcia (Eds.), Teaching of English as a Second and Foreign Language. Boston: Heinle and Heinle.

Oxford, R. L., Park-Oh, Y., Ito, S., \& Sumrall, M. (1993). Japanese by Satellite: Effects of Motivation, Language Learning Styles and Strategies, Gender, Course Level, and Previous Language Learning Experience on Japanese Language Achievement. Foreign Language Annals, 26, 359-371. http://dx.doi.org/10.1111/j.1944-9720.1993.tb02292.x

Oxford, R. L., Crookall, D., Cohen, A., Lavine, R., Nyikos, M., \& Sutter, W. (1990). Strategy Training for Language Learners: Six Situational Case Studies and a Training Model. Foreign Language Annals, 22, 197-216. http://dx.doi.org/10.1111/j.1944-9720.1990.tb00360.x

Paige, R. et al. (2006). Maximizing Study Abroad: A Student's Guide to Strategies for Language and Culture Learning and Use (2nd ed.). Minneapolis, MN: Centre for Advanced Research on Language Acquisition, University of Minnesota.

Redmond, M. V., \& Bunyi, J. M. (1991). The Relationship of Intercultural Communication Competence with Stress and the Handling of Stress as Reported by International Students. International Journal of Intercultural Relations, 17, $235-254$. http://dx.doi.org/10.1016/0147-1767(93)90027-6

Sercu, L. (2002). Autonomous Learning and the Acquisition of Intercultural Communicative Competence: Some Implications for Course Development. Language, Culture \& Curriculum, 15, 61-74. http://dx.doi.org/10.1080/07908310208666633

Thompson, I., \& Rubin, J. (1996). Can Strategy Instruction Improve Listening Comprehension? Foreign Language Annals, 29, 331-342. http://dx.doi.org/10.1111/j.1944-9720.1996.tb01246.x

Zhang, M. (2001). Language Learning Strategies and English Language Proficiency: An Investigation of Chinese ESL Students at NUS. Journal of RELT, 51-73. 